Influence of Thickness Variation on Optical Properties of (Poly Vinyl Alcohol : violet Methyl) Composite

Yaqoob M. Jawad

\title{
Influence of Thickness Variation on Optical Properties of (Poly Vinyl Alcohol : violet Methyl) Composite
}

\author{
Yaqoob M. Jawad \\ Diyala University-College of Sciences - Department of Physics
}

Received: 28 March 2016

Accepted: 22 May 2016

\begin{abstract}
$\underline{\text { Abstract }}$
Poly(vinyl alcohol) doped by (Violet methyl) films with different thicknesses were prepared by casting method. The effects of thicknesses on the optical Characterization of poly (vinyl alcohol) films have been studied. The films show indirect allowed interband transitions that influenced by the thicknesses, the optical energy gap has been increased with increasing the thickness and the localized tail widths have been decreased with increasing the thickness.
\end{abstract}

Keywords: Poly(vinyl alcohol) , Casting method , Optical Properties, Urbach Energy, Influence of thickness variation

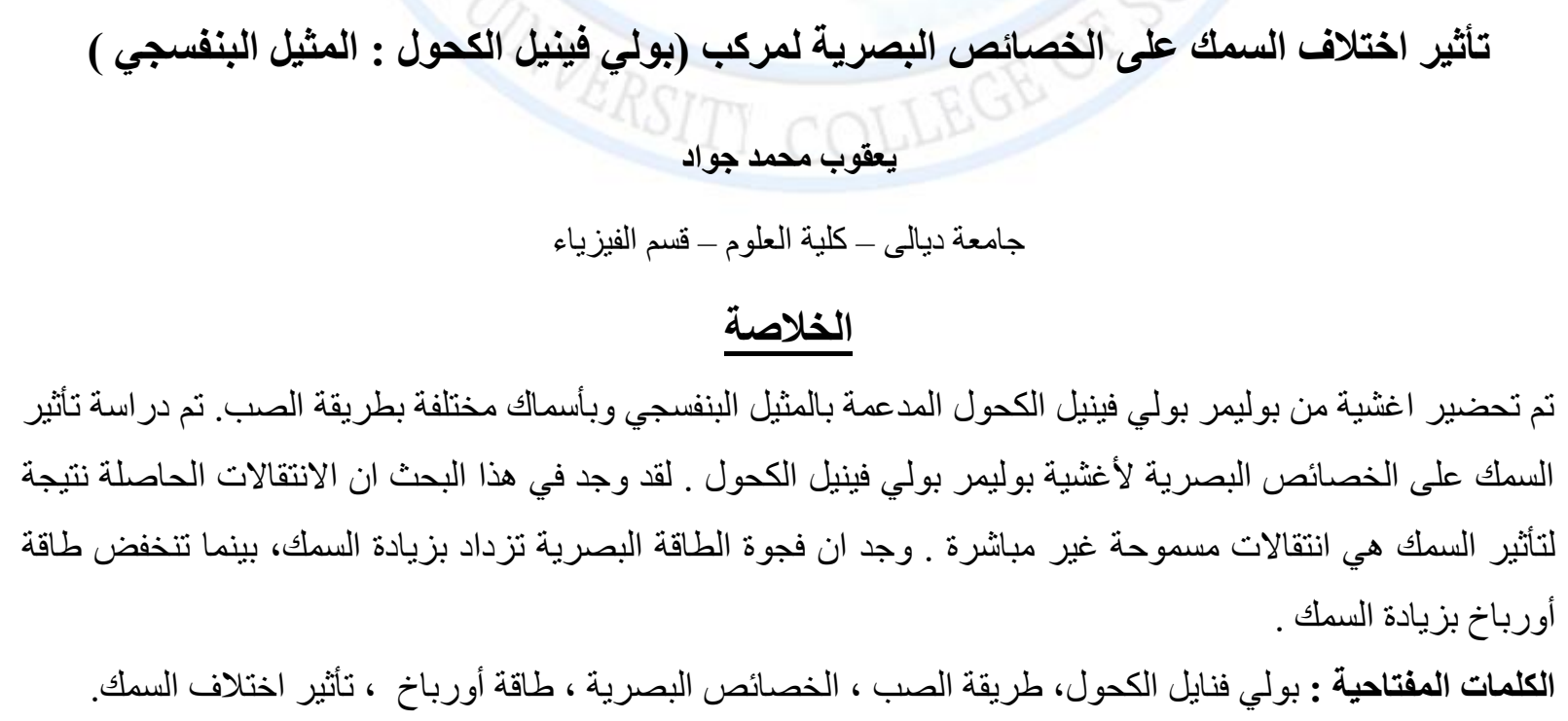




\section{Influence of Thickness Variation on Optical Properties of (Poly Vinyl Alcohol : violet Methyl) Composite}

\section{Yaqoob M. Jawad}

\section{Introduction}

Poly vinyl alcohol (PVA) has been used in many applications since its discovery in 1924 [1]. We have used PVA as a host polymer because PVA is semi - crystalline polymer, good chare storage capacity, having high dielectric strength, flexible light Wight materials and can be produced at a low cost [2-3]. Various composite materials had been recently synthesized by starting from different polymers and a wide variety of dopants like metals, inorganic salts, oxides and other particles. The incorporation of the dopants in polar organic polymers can induce pronounced changes in various Characteristics of polymers in order to modify and improve its Characteristics [4-5].

In the present work is to investigate the optical properties of Poly Vinyl Alcohol (PVA) doped with $4 \%$ of Violet methyl with different thicknesses by casting method.

\section{Experimental details}

Poly vinyl alcohol polymer (PVA) solution was prepared by incorporation deionized distilled water at solid PVA and then stirred by a magnetic stirrer to $60{ }^{\circ} \mathrm{C}$ at one hour, a solution of (Violet methyl) was prepared by incorporation deionized distilled water to (Violet methyl) and then stirred by amagnetic stirrer at room temperature for $(1 / 2 \mathrm{~h})$. Appropriate mixtures of PVA and (Violet methyl) solution were mixed for $(4 \%)$ concentration by a different of thicknesses at $(5 \mu \mathrm{m}, 10 \mu \mathrm{m}, 20 \mu \mathrm{m}$ and $40 \mu \mathrm{m})$.

The solution was poured on flat glass dish. Homogenous films were obtained after drying in oven for $(2 \mathrm{~h})$ at $50{ }^{\circ} \mathrm{C}$. The film thicknesses was measured with a digital micrometer (China Hunan E\&K Tools Company) and the average area was $(3 \times 3) \mathrm{cm}^{2}$. Absorbance and transmittance measurement were carried out using UV/VIS spectrometers in the wave length range $(190-1100) \mathrm{nm}$.

\section{Results and discussion}

The optical transmission spectra as a function of wavelength at range (190-1100) nm is shown in Figure (1). We can observe from this figure that the transmittance decreases with increasing the thickness. Also may be attributed to creation of levels at the energy band by increasing thickness and this leads to the shift of peak to smaller energies. There are no absorption 
Influence of Thickness Variation on Optical Properties of (Poly Vinyl Alcohol : violet Methyl) Composite

Yaqoob M. Jawad

spectrum in the visible region becuase the films are transparent and this result agree with previous studies $[6,7]$.

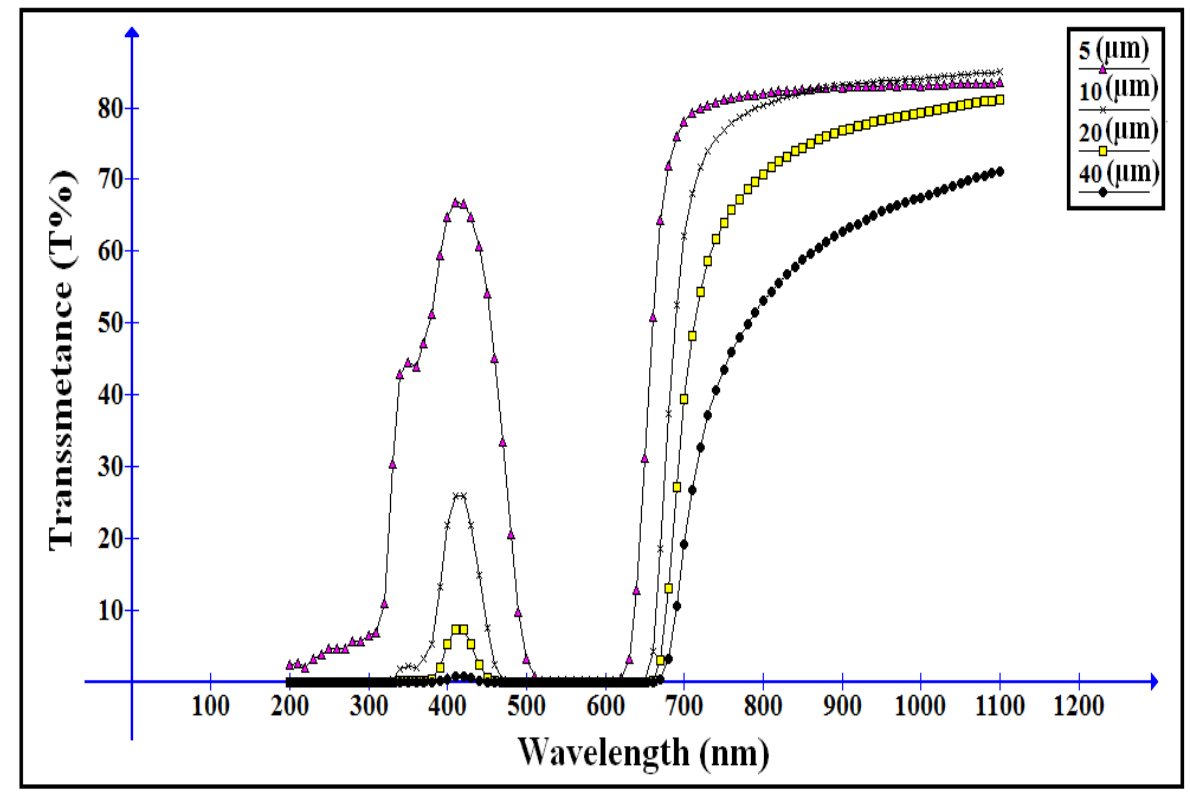

Fig. (1): Transmission Spectra of (PVA- violet Methyl) with different thickness films.

Fig. (2). shows the Absorbance as a function of wavelength was found to increase with increasing the thickness.

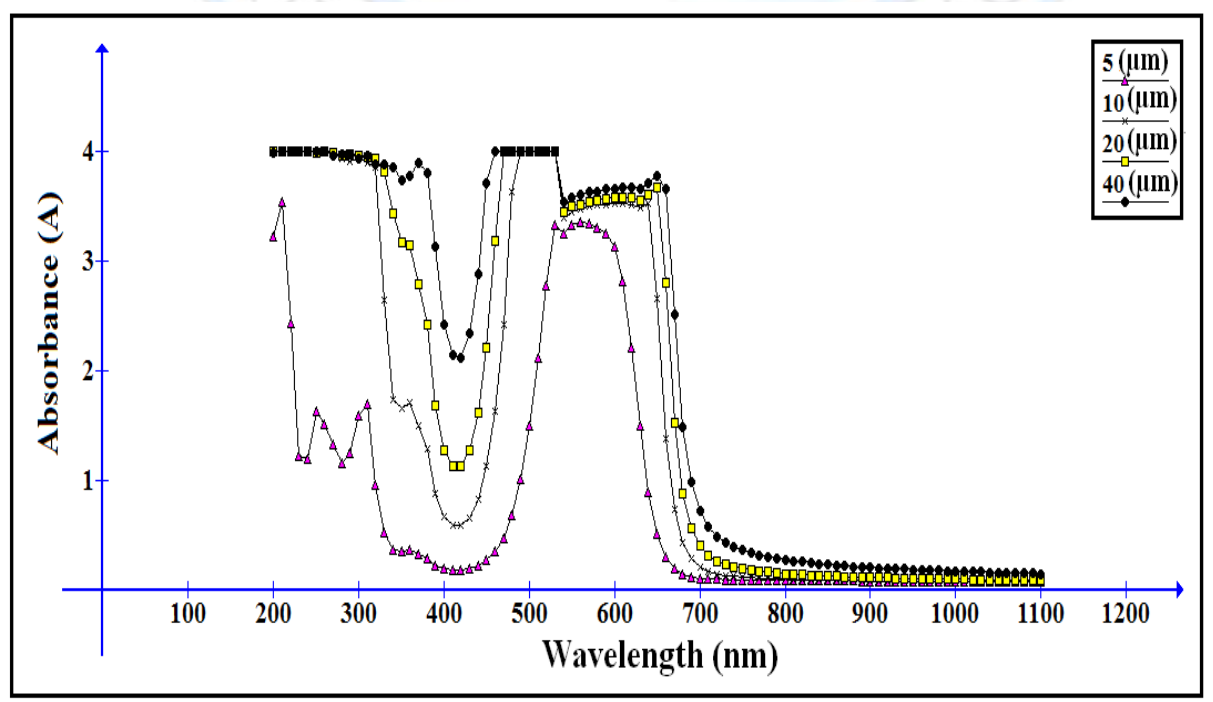

Fig. (2): Absorbance of (PVA- violet Methyl) with different thickness films. 
Influence of Thickness Variation on Optical Properties of (Poly Vinyl Alcohol : violet Methyl) Composite

Yaqoob M. Jawad

Fig. (3) Shows the reflectance as a function of wavelength

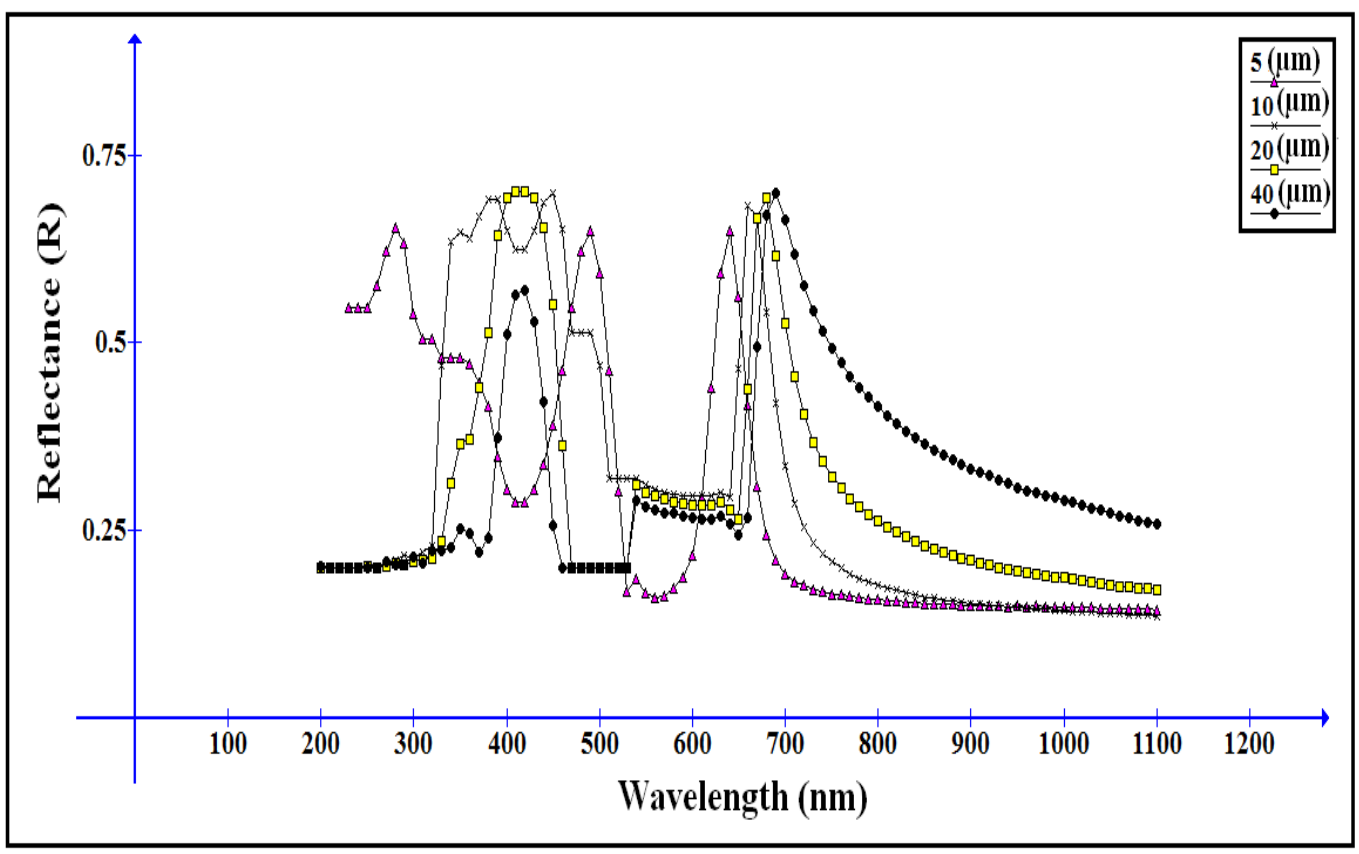

Fig. (3): Reflectance of (PVA- violet Methyl) with different thickness films.

The following relation could be use for calculating the absorption coefficient $(\alpha)$ [8]:

$$
\alpha=\frac{2.303 A}{l}
$$

Where (A) is the absorption and $(l)$ is the thickness of film.

Fig. (4) show that absorption coefficient increasing with increases of thickness, at short wavelength $(\alpha)$ takes higher value and then increases with decreasing $(\lambda)$ (increasing photon energy). 
Influence of Thickness Variation on Optical Properties of (Poly Vinyl Alcohol : violet Methyl) Composite

Yaqoob M. Jawad

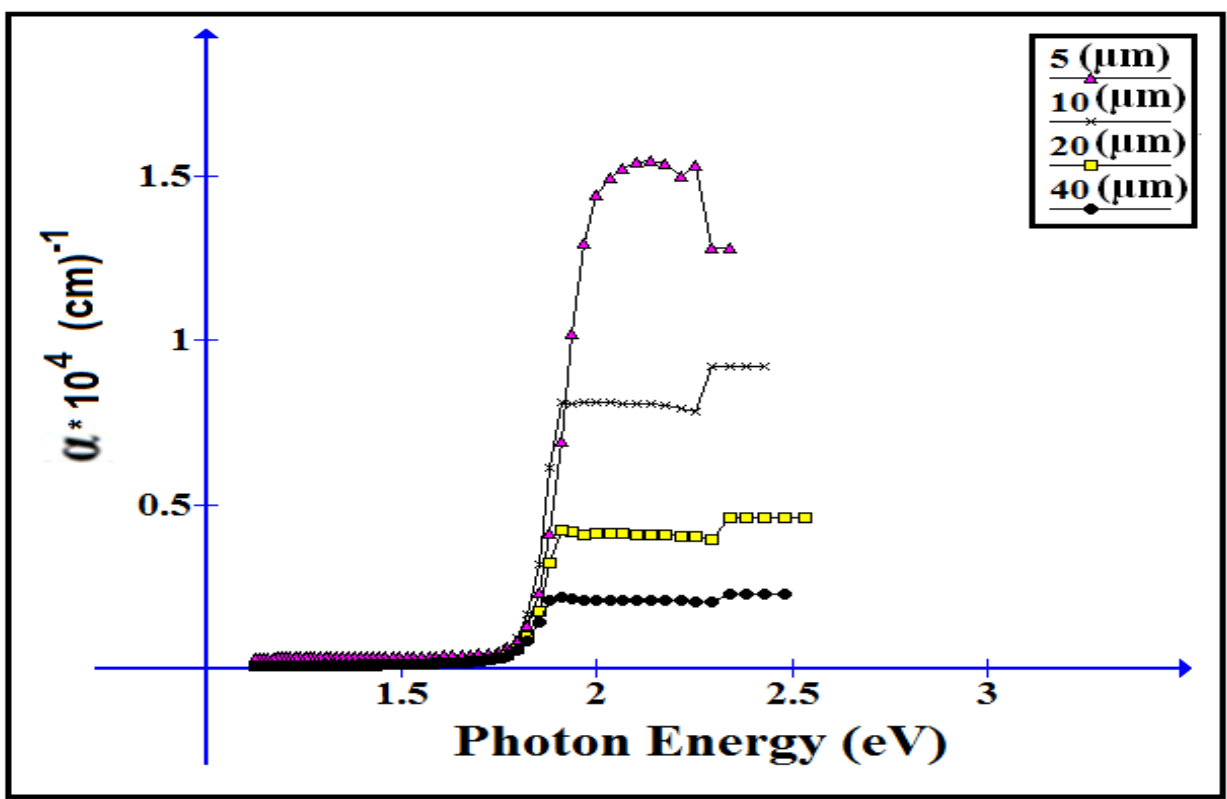

Fig. (4): Absorption Coefficient of (PVA- violet Methyl) with different thickness films.

The optical energy gap of the films for allowed indirect transition is determined by the following relation [9]:

$$
(\alpha h f)^{n}=B(h f-E g)
$$

Where $\left(\mathrm{E}_{\mathrm{g}}\right)$ is the optical energy gap of films, $(\mathrm{B})$ is a constant and $(\mathrm{h} v)$ is the incident photon energy . the optical energy gap can estimated by plotting $(\alpha h v)^{1 / 2}$ versus photon energy $(h v)$, then extrapolating the straight line part in plot to the photon energy axis Figures (5) shows the variation of optical energy gap of (PVA: Violet methyl) for different thickness films. The energy gap increases from $(1.72,1.75,1.78,1.80) \mathrm{eV}$ as thickness increases from $(5,10,20,40)$ $\mu \mathrm{m}$. This may be explained by invoking of occurrence to local cross linking within the amorphous phase of polymer, such a way as to increase the degree to ordering in these parts [10], process Similar behavior had been noticed by Shawki et al. [11]. 
Influence of Thickness Variation on Optical Properties of (Poly Vinyl Alcohol : violet Methyl) Composite

Yaqoob M. Jawad

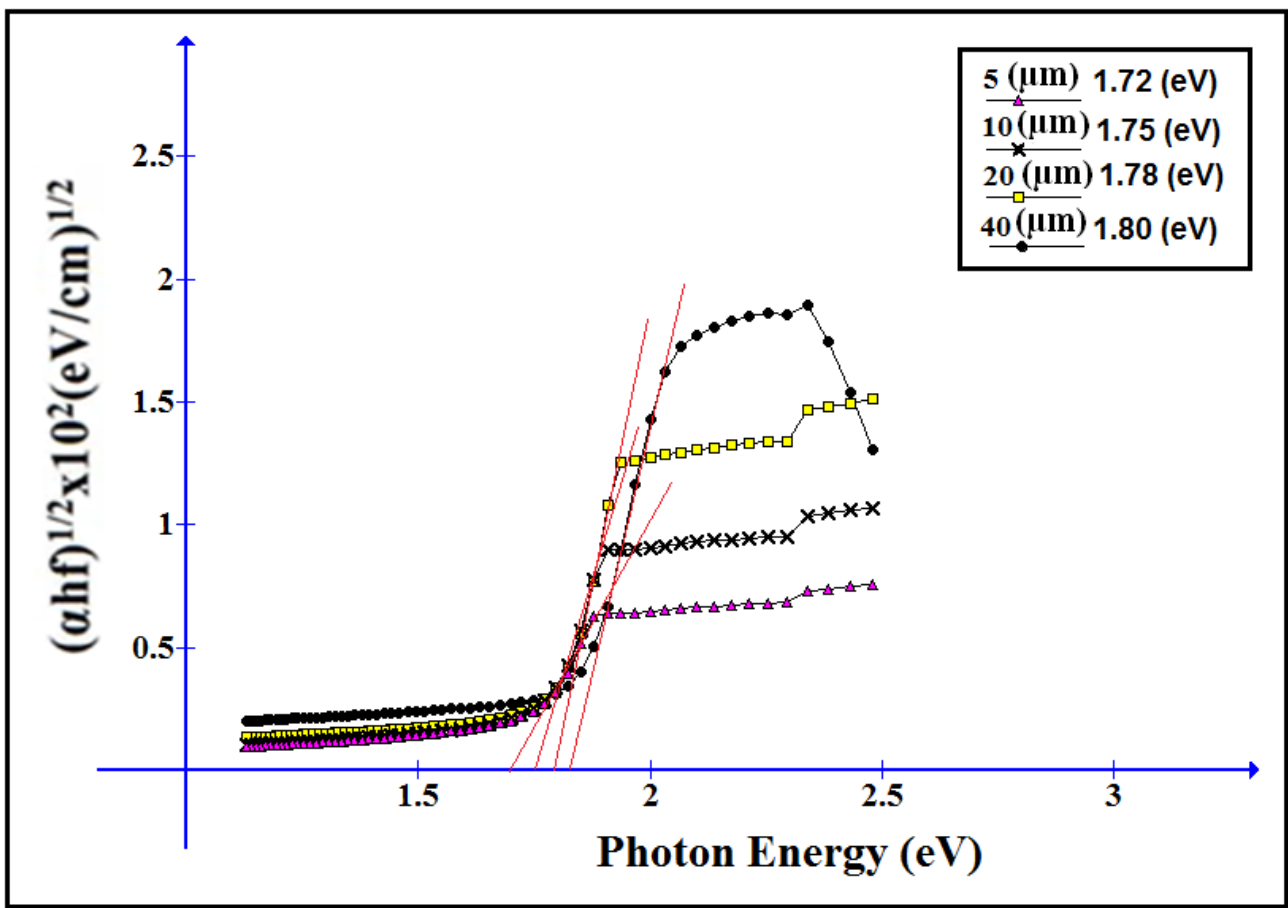

Fig. (5): Optical Energy Band Gap of (PVA- violet Methyl) with different thickness

films.

The absorption is due to the electronic transitions between the valence-band-tail and the conduction-band states and depends exponentially on the photon energy according to the Urbach relation as follows [12]:

$$
\alpha=\alpha_{0}(\mathbf{h v} / \mathbf{E e})
$$

Where ( $E_{\mathrm{e}}$ ) is the Urbach energy, $(\mathrm{h} v)$ is photon energy. Fig. (6) show the relationship between $[\ln (\alpha)]$ and the photon energy. The value of $\left(E_{e}\right)$ decreased from about $(0.088 \mathrm{eV})$ for the $(5$ $\mu \mathrm{m}),(0.072 \mathrm{eV})$ for the $(10 \mu \mathrm{m}),(0.065 \mathrm{eV})$ for the $(20 \mu \mathrm{m})$ and $(0.061 \mathrm{eV})$ for the $(40 \mu \mathrm{m})$. Table (1) give the values of optical energy band gap and urbach energy. 
Influence of Thickness Variation on Optical Properties of (Poly Vinyl Alcohol : violet Methyl) Composite

Yaqoob M. Jawad

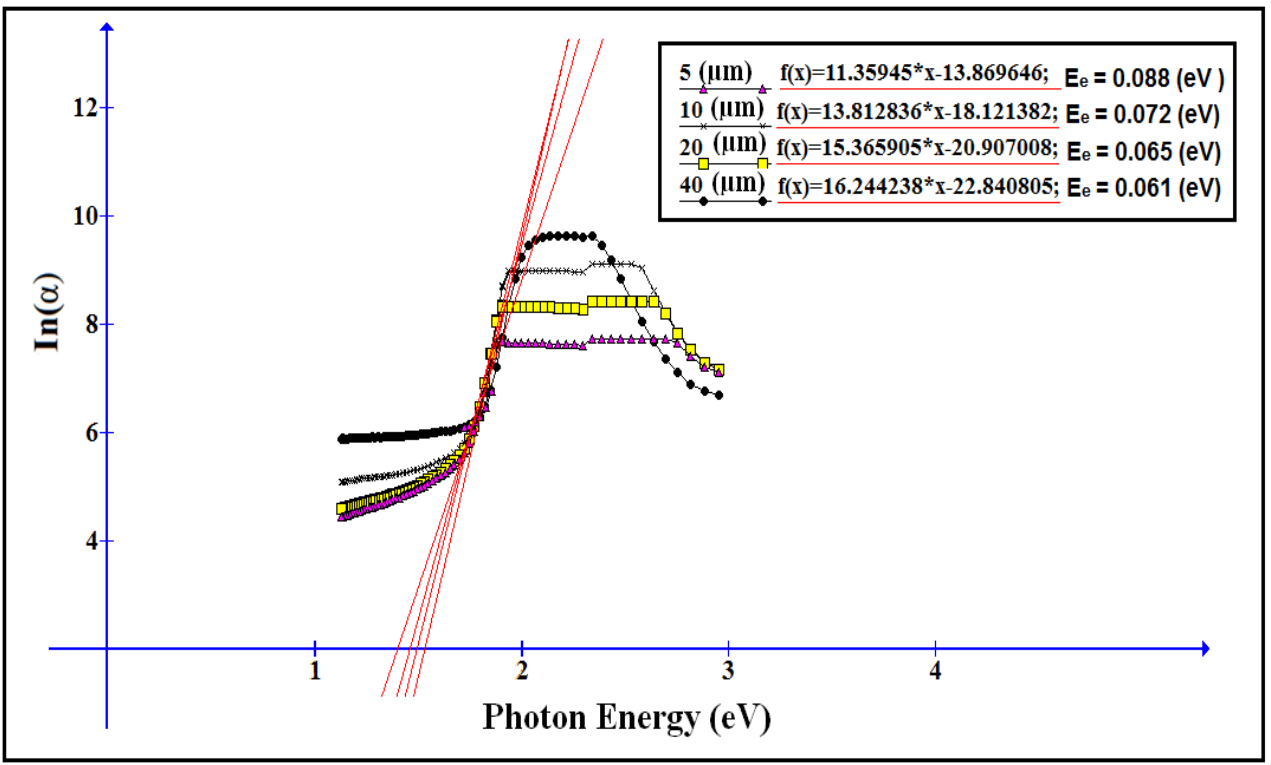

Fig. (6) : Relation between In $\alpha$ and photon energy for (PVA- violet Methyl) with different thickness films.

Table (1)

\begin{tabular}{|c|c|c|}
\hline Thickness Films $(\boldsymbol{\mu m})$ & $\begin{array}{c}\text { Optical Energy Gap } \\
(\mathbf{e V})\end{array}$ & $\begin{array}{c}\text { Urbach Energy } \\
(\mathbf{e V})\end{array}$ \\
\hline 5 & $\mathbf{1 . 7 2}$ & $\mathbf{0 . 0 8 8}$ \\
\hline 10 & $\mathbf{1 . 7 5}$ & $\mathbf{0 . 0 7 2}$ \\
\hline 20 & $\mathbf{1 . 7 8}$ & $\mathbf{0 . 0 6 5}$ \\
\hline 40 & $\mathbf{1 . 8 0}$ & $\mathbf{0 . 0 6 2}$ \\
\hline
\end{tabular}

\section{Conclusions}

The PVA doped violet Methyl with different thickness films. Films have been prepared successfully by casting method, The films show indirect allowed inter band transitions that influenced by the thicknesses, the optical energy gap has been increased from about $\mathrm{eV})$ for the $(5 \mu \mathrm{m}),(1.75 \mathrm{eV})$ for the $(10 \mu \mathrm{m}),(1.78 \mathrm{eV})$ for the $(20 \mu \mathrm{m})$ and $(1.80 \mathrm{eV})$ for the $(40 \mu \mathrm{m})$ and the localized tail widths have been decreased from about $(0.088 \mathrm{eV})$ for the $(5 \mu \mathrm{m}),(0.072 \mathrm{eV})$ for the $(10 \mu \mathrm{m}),(0.065 \mathrm{eV})$ for the $(20 \mu \mathrm{m})$ and $(0.061 \mathrm{eV})$ for the $(40 \mu \mathrm{m})$. 


\section{Influence of Thickness Variation on Optical Properties of} (Poly Vinyl Alcohol : violet Methyl) Composite

Yaqoob M. Jawad

\section{References}

1. Polymer, "Effects of crosslinking on the mechanical and thermal properties of poly(vinyl alcohol)”, (2000), M. Krumova, D. López, R. Benavente, C. Mijangos, J.M. Perenã, Vol.41, P.P. (9265-9272).

2. J. The first scientific conference the collage of sciences, "Characterization and optical properties of lead doped polyvinyl a lcohol films",(2013), Muna M. Abbas, J. Al wan and Inaam M. Adbu lmajeed PP. $(30-36)$.

3. J. Science and Technology, "Electrical and optical properties of PVA/ LiI polymer Electrolty films" , (2012), Hamed M. Ahmad, Sabah H. Sabeeh, Sarkawt and A. Hussen, Vol. (1), No. (6).

4. [4] J. Al-Nahrain University, "Study the optical properties of poly(vinl a lcohol) doped cupper chloride", (2013), Mustafa Abdalh, Osama Hamood and Emad Yousif Vol. (16), No.(1), PP.(17-20).

5. J. Materials Chemistry and Physics, "Poly (vinly a lcohol) thin film filled with CdSe $-\mathrm{ZnS}$ quantum dots: Fabrication, characterization and optical properties", (2010), Baoting Suo, Xin Wu, Daniel Chen, Andrew Wang and Zhanhu Guo Vol.(119), PP.(237-242).

6. Polymer Testing, "Effect of the Molecular Weights on the Optical and Mechanical Properties of Poly (Vinyl Alcohol) Films" , (2002) , K. A. Abd El-Kader, S. F. Abdel Hamied, A. B. Mansour, A. M. Y El- Lawindy, F. El- Tantaway, Vol.21 , NO. 7 P.P.(847$850)$.

7. Diyala Journal For Pure Science, "Effect of Thickness on The Optical Parameters of PVA:Ag" , (July 2011), Sami Salman Chiad , Nadir Fadhil Habubi , Saad Farhan Oboudi , Muhammad Hameed Abdul-Allah, Vol: 7, No: 3.

8. Thin Solid Films, "Properties of nanocrystalline zinc oxide thin films prepared by thermal decomposition of electrodeposited zinc peroxide", (2008), X. Han, R. Liu, W. Chen, Z. Xu, Vol. 516, P.P. (4025-4029). 
Influence of Thickness Variation on Optical Properties of (Poly Vinyl Alcohol : violet Methyl) Composite

Yaqoob M. Jawad

9. Applied Surface Science, "Improvement in Mechanical and Optical Properties of Vapour Chopped Vacuum Evaporated PANI/PMMA Composite Thin Film", (2007), J.B. Yadav , R.K. Puri , Vol. 254 , No. 5 , p.p 1382-1388,.

10. Applied Surface Science, " Physical Properties of ZnO Thin Films Deposited by Spray Pyrolysis Technique " , (2006), A. Ashour, M. A. Kaid, N. Z. El-Sayed and A. A. Ibrahim, Vol.252, No.22, P.P.(7844-7848).

11. J.Thi-Qar Sci.,"Influence of Thickness on Optical Properties of (PVA-CoCl2) films", (2013) , Shawki kh. Muhammad, Muhammad H.A, Widad H. A, Vol.4 (1)

12. J. Non-Cryst. Solids, "States in The Gap" , (1972) , J. Tauc, A. Menth, (8-10), 569-585. 